\title{
TRATAMENTO DOS EFLUENTES DA AULA DE QUÍMICA ANALÍTICA DA UECE/FAEC A PARTIR DA PRODUÇÃO DE CARVÃO ATIVADO DE BORRA DE CAFÉ
}

\author{
Jessyca Nayara Mascarenhas Lima ${ }^{1}$ \\ Orivaldo da Silva Lacerda Junior ${ }^{2}$ \\ Francisco Elton Siqueira Júnior ${ }^{3}$ \\ José Miranda Amâncio 4 \\ Maria Carolaine Aurélio Fernandes Rosendo 5 \\ Sebastiana Vieira Siqueira ${ }^{6}$
}

\begin{abstract}
RESUMO: O presente estudo tem por objetivo o tratamento dos efluentes gerados nas aulas de Química Analítica com filtração com carvão ativado a partir da borra de café residual no Campus da UECE/FAEC. Foi preparado carvão ativado utilizando ativante químico $\mathrm{NaOH}$ e calcinado a $550{ }^{\circ} \mathrm{C}$ o carvão foi caracterizado por difração de raios-X e FTIR. Os resultados de DRX demonstraram um material com característica amorfo, já o FTIR confirmou vibrações em torno de 1600 e $1400 \mathrm{~cm}^{-1}$ referente ao estiramento de ligações C-C e $\mathrm{C}=\mathrm{C}$ de aromáticos ou de anéis de ligninas, típicos de material carbonáceo. A partir dos ensaios de adsorção para três tipos de efluentes, os resultados demonstraram que o carvão foi eficiente para os efluentes dos frascos i e 3 com rendimento de $99 \%$ com reciclo de reuso de 5 vezes, sem perda de adsorção.
\end{abstract}

Palavra- chaves: Resíduos de aula. Tratamento. Carvão ativado.

ABSTRACT: The present study aims to treat the effluents generated in Analytical Chemistry classes with filtration with activated carbon from residual coffee grounds at the UECE / FAEC Campus. Activated charcoal was prepared using chemical activator $\mathrm{NaOH}$ and calcined at $550^{\circ} \mathrm{C}$. The charcoal was characterized by X-ray and FTIR diffraction. The XRD results showed a material with an amorphous characteristic, whereas the FTIR confirmed vibrations around 1600 and $1400 \mathrm{~cm}-\mathrm{I}$ referring to the stretching of aromatic C-C and $\mathrm{C}=\mathrm{C}$ bonds or lignin rings, typical of carbonaceous material. From the adsorption tests for three types of effluents, the results showed that the coal was efficient for the effluents of flasks I and 3 with $99 \%$ yield with 5 times reuse recycle, without loss of adsorption.

Keywords: Class waste. Treatment. Activated carbon.

\footnotetext{
${ }^{1}$ Aluna de IC da Universidade Regional do Cariri-URCA. ORCID.https://orcid.org/oooo-oooz-5225493X,jessyca.lima@urca.br.

${ }_{2}$ Professor da Universidade Estadual do Ceará-Faculdade de Educação de CrateúsFAEC/UECE, https://orcid.org/oooo-ooor-878o-7285E-mail: olacerda_jr@hotmal.com

3 Aluno de IC da Universidade Estadual do Ceará-Faculdade de Educação de CrateúsFAEC/UECE, https://orcid.org/oooo-oooi-9475-575, eltonbigmaster@gmail.com

${ }^{4}$ Aluno de IC da Universidade Estadual do Ceará-Faculdade de Educação de CrateúsFAEC/UECE. https://orcid.org/oooo-ooo2-7879-7457.

5 Aluna de IC da Universidade Estadual do Ceará-Faculdade de Educação de CrateúsFAEC/UECE. https://orcid.org/oooo-ooo2-7190-968X.

${ }^{6}$ Aluna de IC da Universidade Estadual do Ceará-Faculdade de Educação de Crateús-FAEC/UECE. https://orcid.org/oooo-oooz-8665-6398
} 


\section{INTRODUÇÃO}

A quantidade dos resíduos químicos gerados pelas universidades nos laboratórios de ensino vem aumentando cada vez mais. Essa afirmação tem o seu lado positivo, pois se observa que com o aumento da oferta do número de cursos superiores aumentou, também, o número de pessoas que têm acesso aos mesmos (BENTO e PAIM, 20I4). Assim sendo, a geração pontual de resíduos químicos configurou-se em um dos problemas a serem contornados, sobretudo nas universidades. Todavia, sabe-se que os profissionais que atuam nesse segmento não receberam formação adequada para lidar com esses problemas nos bancos escolares, também porque as próprias instituições de ensino e pesquisa não tratavam seus resíduos químicos de atividades laboratoriais até pouco tempo atrás (Nolasco, Tavares e Bendassolli, 2006).

DI VITTA (2012) e MARINHO et. al., (20II), ressaltam que os resíduos gerados em laboratório de química de pesquisa e ensino são classificados em Classe I (perigosos) e Classe II (não perigosos). SILVA et. al., (2013) relata que esses resíduos podem ser tratados por diversas formas: neutralização, redução, oxidação, precipitação, destilação, biodegradação, troca iônica, processos oxidativos e principalmente por adsorção, este último processo, utilizado para reter íons, normalmente de metais pesados presentes em soluções aquosas. Esse processo pode ser efetuado pelo emprego de carvão ativado ou biomassa. SILVA et. al., (2013) ressalta ainda, que os resíduos gerados em atividades experimentais em aulas de Química apresentam muitas vezes as seguintes características: mau cheiro; presença de misturas de fases líquidas e sólidas; colorações decorrentes de misturas de substâncias coloridas ou de reações lentas com o ar (oxidação, por exemplo) sob a ação da luz ou mesmo entre componentes do resíduo; presença de borras, lacas e gomas de aspecto visual desagradável.

A falta de um programa de gerenciamento ou de um tratamento prévio na maioria das instituições de ensino e pesquisa acarreta um descarte pouco consciente dos materiais residuais, por meio de pias dos laboratórios ou mesmo em lixos comuns. Em alguns casos, tem-se a geração de passivos ambientais expressivos, que vão se acumulando ao longo do tempo à espera de um fortuito tratamento 
(FIGUERÊDO, 2006). Frente a esses descasos vários pesquisadores vêm desenvolvendo técnicas para tratamento de resíduos de laboratório de ensino IFS. GIOVANNI et. al., (2008) propôs o tratamento de cromo residual por precipitação química utilizando $\mathrm{NaOH}$ como preciptante; SILVA et. al., (2013) relata o tratamento de resíduos ácidos e básicos, precipitados e de oxirreduções, AFONSO et. al., (2005) realizou uma análise sistemática de reagentes e resíduos sem identificação e DI VITTA, (2012) enfatizou em seu trabalho o gerenciamento de resíduo químicos gerados em laboratórios de ensino e pesquisa, no entanto, todos esse procedimentos utilizam produtos químicos ou geram subprodutos.

Neste sentido, a Universidade Estadual do Ceará (UECE/FAEC) polo Crateús, pode contribuir com a difusão de tecnologia para a minimização, tratamento e recuperação de resíduos químicos, visto que possuem laboratórios que geram estes resíduos, além de destacada a construção de um novo Campus na cidade, e cujo crescimento prevê para os próximos anos a implantação de pelo menos mais cursos de graduação como potenciais geradores de resíduos químicos em laboratórios de ensino e pesquisa.

Diante de todos os problemas relacionados pelo descarte indiscriminado de resíduos provenientes de aulas em universidades, algumas instituições de ensino vêm implantando um sistema de gerenciamento e tratamento de resíduos. O sistema de gerenciamento faz com que alunos, professores e funcionários se conscientizem e contribuem para um descarte correto dos resíduos (AFONSO, 2003).

Desta forma o tratamento de efluente de laboratório de química contendo íons positivos e negativos de forma rápida e econômica, sem a geração de subprodutos é utilizado o processo de adsorção com carvão ativado. A adsorção hoje é o método alternativo para remoção total ou parcial de contaminantes ambientais. Nessa prerrogativa, o carvão ativado (CA) possui alta capacidade de adsorção, baixa reatividade térmica, resistência a grandes variações de $\mathrm{pH}$ no meio, além de poder ser regenerado e recuperado do contaminante para a ser reutilizado. $O$ carvão ativado pode ser de fácil obtenção a parir de qualquer material vegetal, semente de melão ou melancia, casca de coco, borra de café e entre outras, pelo processo de calcinação ou 
pirólise e ativação química com $\mathrm{ZnCl}_{2}, \mathrm{KOH}$ e $\mathrm{H}_{3} \mathrm{PO}_{4}$ e $\mathrm{NaOH}$ (SANTOS et. al., 2015; PINTO et. al., 2012; DE SALES et. al., 2015 e BRUM et. al., 2011).

Frente ao exposto, o presente estudo teve como objetivo tratar os resíduos gerados nas aulas de Química Analíticas em uma Instituição de Ensino superior, a universidade Estadual do Ceará (UECE/FAEC), utilizando o procedimento de adsorção, utilizando carvão ativado oriundo de borra de café residual do próprio campus, avaliando a concentração dos efluentes antes e depois por técnicas espectroscópicas de UV-Visível.

\section{MATERIAL E MÉTODOS/METODOLOGIA}

O estudo se enquadra, quanto aos objetivos, como exploratório, pois pretende atingir uma área na qual há pouco conhecimento acumulado; descritivo, porque descreve as medidas adotadas para o gerenciamento de resíduos e efluentes laboratoriais e os resultados encontrados; e explicativa, porque explica os procedimentos adotados para o correto gerenciamento dos resíduos e efluentes gerados nos laboratórios quanto à abordagem, como qualiquantitativo; e quanto aos meios, como bibliográfico e de campo (VERGARA, 2015).

Foram tratados os resíduos das disciplinas de química Analítica I (volumetria ácido e base, volumetria de precipitação e volumetria de oxirredução e volumetria de complexação) durante os semestres de 2019/02 no laboratório de química do campus do UECE/FAEC. Dados que a origem dos resíduos considerados pode ser conhecidos a partir das práticas experimentais das disciplinas, podem-se listar, a nível qualitativo e quantitativo, a presença de cátions e ânions outros compostos presentes nos resíduos contendo um determinado elemento de interesse, conforme foi listado na tabela or.

Tabela or. Lista de analitos presentes nos resíduos dos elementos de interesse

\begin{tabular}{|l|l|l|l|}
\hline Frasco I & Solução Azul & Cátions & $\mathrm{Cu}^{2+}(\mathrm{o}$, oImol/L ou I596 mg/L) \\
\hline Frasco 2 & Solução Amarelada & Cátions & $\mathrm{Cr}_{2} \mathrm{O}_{7}^{2-}(\mathrm{o}, 0 \mathrm{~mol} / \mathrm{L})$ ou 294I mg/L \\
\hline Frasco 3 & Solução Roxo intenso & Cátions e ânions & $\begin{array}{l}\mathrm{MnO}{ }_{4}^{-}(\mathrm{o}, 05 \mathrm{~mol} / \mathrm{L}) \quad \text { ou 790,2 } \\
\mathrm{mg} / \mathrm{L}\end{array}$ \\
\hline Frasco 4 & Solução laranja intenso & Cátions & $\mathrm{Fe}^{3+}(\mathrm{o}, 05 \mathrm{~mol} / \mathrm{L})$ ou 8II mg/L \\
\hline
\end{tabular}


Após tratamento desses resíduos por adsorção em carvão ativado, água residual obtida após a filtração, foi analisado por UV-visível e despejados na pia corretamente.

Para produção do carvão ativado foi utilizado como material vegetal a borra de café, cedida pela cozinha da UECE/FAEC. A borra de café residual (BCR) foi seca a $100{ }^{\circ} \mathrm{C}$ por 2 horas, seguida de impregnação do ativante hidróxido de sódio $(\mathrm{NaOH})$, na proporção 2:1 $(\mathrm{m} / \mathrm{m})$ e colocada numa chapa aquecedora a $150^{\circ} \mathrm{C}$ por agitação constante, até total evaporação. Após esse procedimento, a borra ativada foi calcinada a $500^{\circ} \mathrm{C}$ por 4 horas, após esse procedimento o carvão ativado foi lavado a vácuo em funil de büchner com solução $\mathrm{HCl}$ o, $\mathrm{N}$, seguida de água destilada até total remoção do ativante químico. O carvão obtido da borra de café foi então nomeado (CABRC).

O carvão ativado foi caracterizado por técnica de difração de Raios-X, as fases cristalográficas e os tamanhos de partículas foram determinados pelos dados coletados método do pó, Os dados de DRX das amostras foram registrados em um difratômetro, Shimadzu, modelo XRD-6ooo, com fonte de radiação de $\mathrm{CuK} \alpha=$ $0,15418 \mathrm{~nm}$, corrente de $30 \mathrm{~mA}$ e tensão de $40 \mathrm{kV}$, em velocidade de varredura $0,02^{\circ} \cdot \min ^{-1}$ no intervalo de 10 a $60^{\circ} / 200$ na Universidade Federal do AmazonasUFAM.

Também foi utilizado a Espectroscopia na região do Infravermelho (IV) Os grupos funcionais presentes nas amostras foram determinados a partir de espectros obtidos por modo de transmissão em um espectrômetro Nicolet, modelo IR-200, com 32 varreduras na faixa de 400 a $4000 \mathrm{~cm}^{-1}$ e resolução de $4 \mathrm{~cm}^{-1}$. A amostra foi misturada com $\mathrm{KBr}$ na proporção ı:ıo e m disco (formato pastilha).

O teste da concentração de lixiviação do catalisador foi determinado por meio de espectrofotometria na região do UV/VIS, com equipamento Shimadzu, Modelo UV I65oPC, com varredura de 800 a $200 \mathrm{~nm}$ e resolução de I $\mathrm{nm}$. O monitoramento da presença do $\mathrm{Ni}^{2+}$ e $\mathrm{Cu}^{2+}$ foram pelos seus cumprimentos de onda respectivamente $450 \mathrm{~nm}$. e $595 \mathrm{~nm}$. Para cromo $\left(\mathrm{Cr}_{2} \mathrm{O}_{7}{ }^{2-}\right)$ foi de $540 \mathrm{~nm}$, para o permanganato $\left(\mathrm{MnO}_{4}{ }^{-}\right)$ foi de 520 a $560 \mathrm{~nm}$ e para o Ferro foi de $510 \mathrm{~nm}$ (Bento e Paim, 2015). 
Para a determinação da curva padrão foram preparadas soluções de referência contendo $\mathrm{Cu}$ e $\mathrm{Cr}$ a partir da diluição de uma solução estoque com concentração de Ioo $\mathrm{mg} / \mathrm{L}$ preparado com reagente de sulfato de cobre $\left(\mathrm{CuSO}_{4}\right)$ e $100 \mathrm{mg} / \mathrm{L}$ de dicromato de potássio $\left(\mathrm{K}_{2} \mathrm{Cr}_{2} \mathrm{O}_{7}\right)$. Em seguida foram feitas as diluições para mais 7 soluções nas quais as concentrações variaram: 0,5 a $2,5 \mathrm{mg} / \mathrm{L}$ de $\mathrm{Cu}$ e $\mathrm{Cr}$ (QUEIROGA e BARBALHO, 2018). Para determinação da curva padrão de ferro e permanganato foram preparado soluções contendo $\mathrm{Fe}$ e $\mathrm{Mn}$ a partir de soluções padrões de cloreto de ferro $\left(\mathrm{FeCl}_{3}\right)$ e permanganato $\left(\mathrm{K}_{2} \mathrm{MnO}_{4}\right)$ com concentração de Iooo $\mathrm{mg} / \mathrm{L}$. Em seguida foram feitas as diluições para mais seis diluições nas quais as concentrações variaram: 50 a $400 \mathrm{mg} / \mathrm{L}(\mathrm{BENTO}$ e PAIM, 2015).

\section{RESULTADOS E DISCUSSÃO}

A curva analítica foi traçada para o elemento cobre $(\mathrm{Cu})$ (Figura $\mathrm{I}$ ), cromo $(\mathrm{Cr})$ (Figura 2), permanganato $(\mathrm{Mn})($ Figura 3$)$ e ferro $(\mathrm{Fe})($ Figura 4$)$, sendo obtido um coeficiente de correlação $\left(R^{2}\right)$ próximo a o,999 (Figura I). Trata-se de uma técnica robusta e de baixo custo em comparação com outras técnicas espectrométricas (QUEIROGA e BARBALHO, 2018).

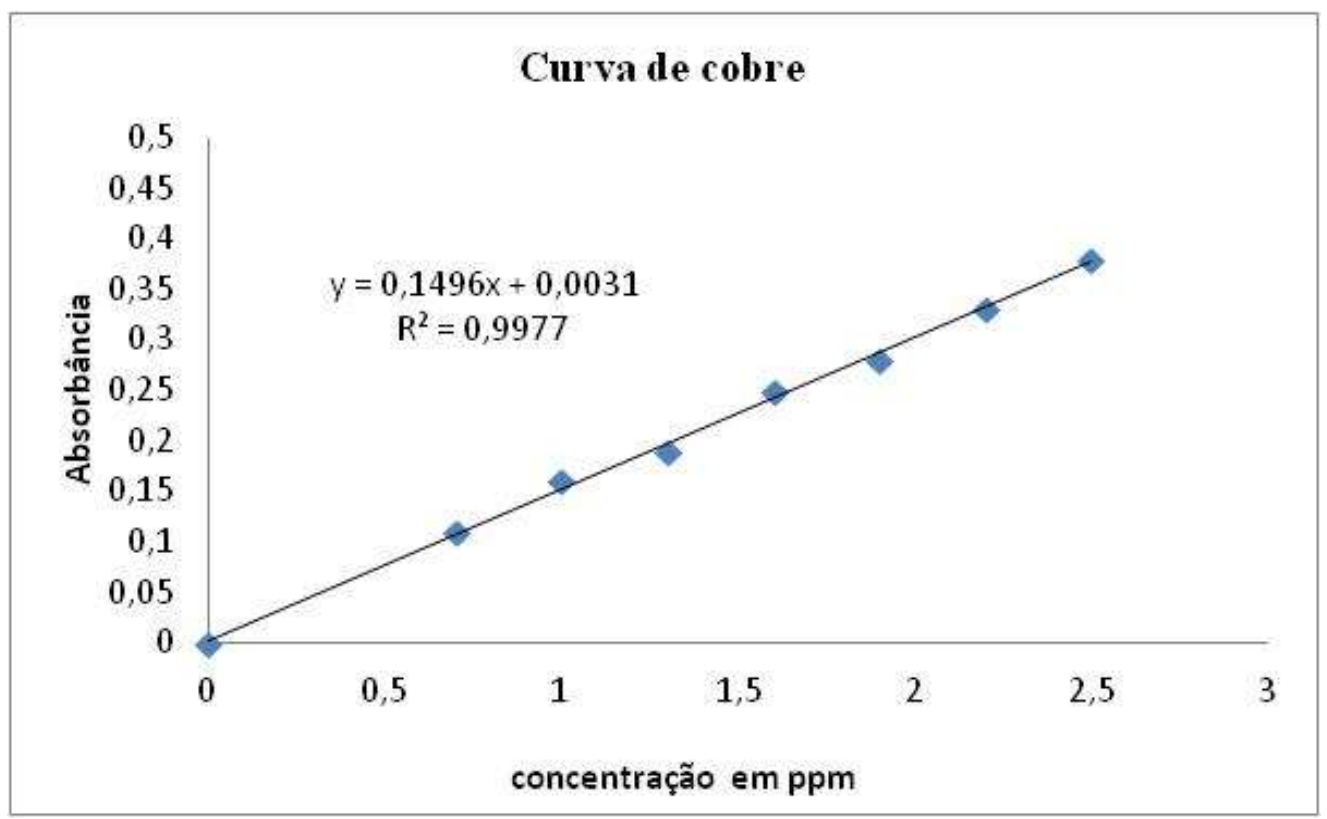

Figura r. Curva padrão de cobre-sulfato de cobre. 


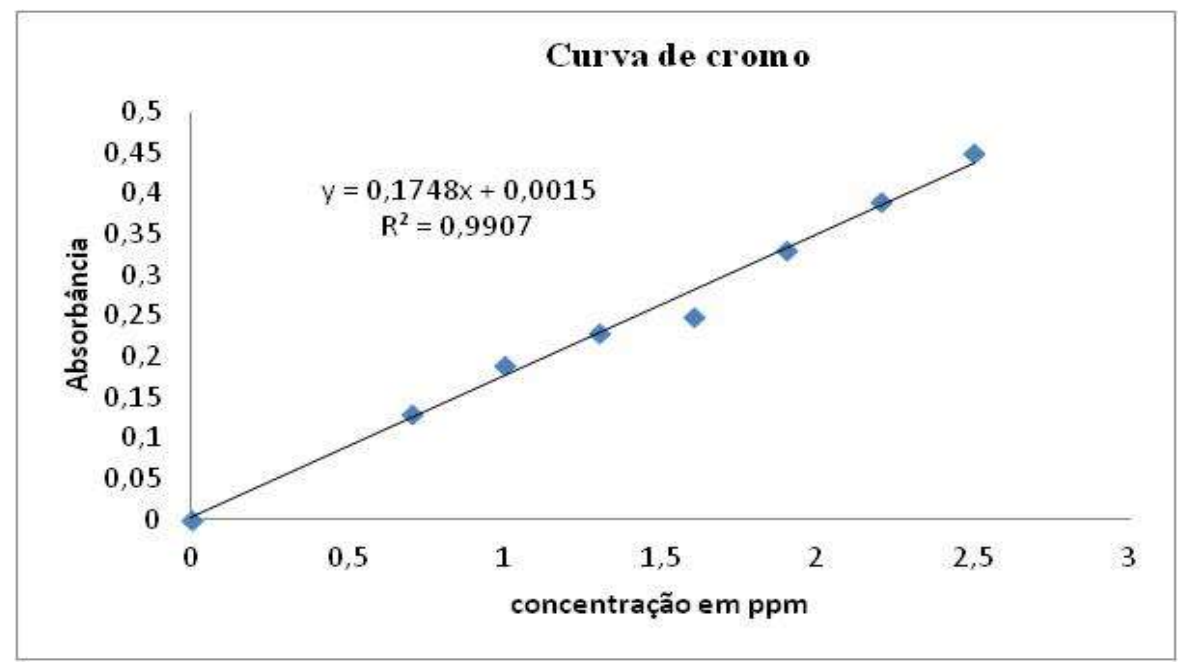

Figura 2. Curva padrão de cromo-dicromato de potássio.

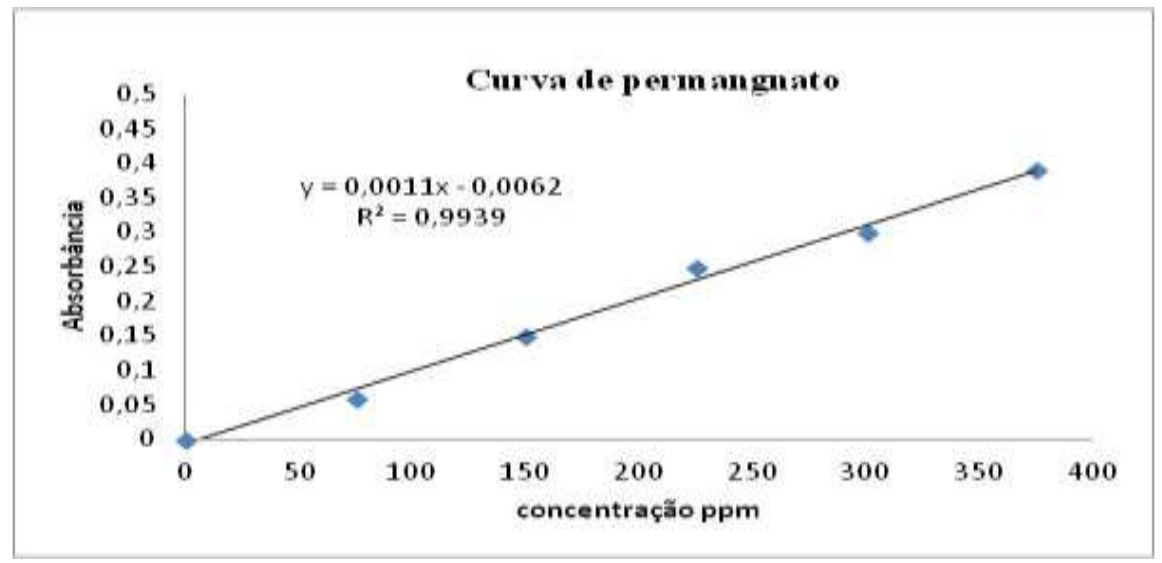

Figura 3. Curva padrão de permanganato-permanganato de potássio.

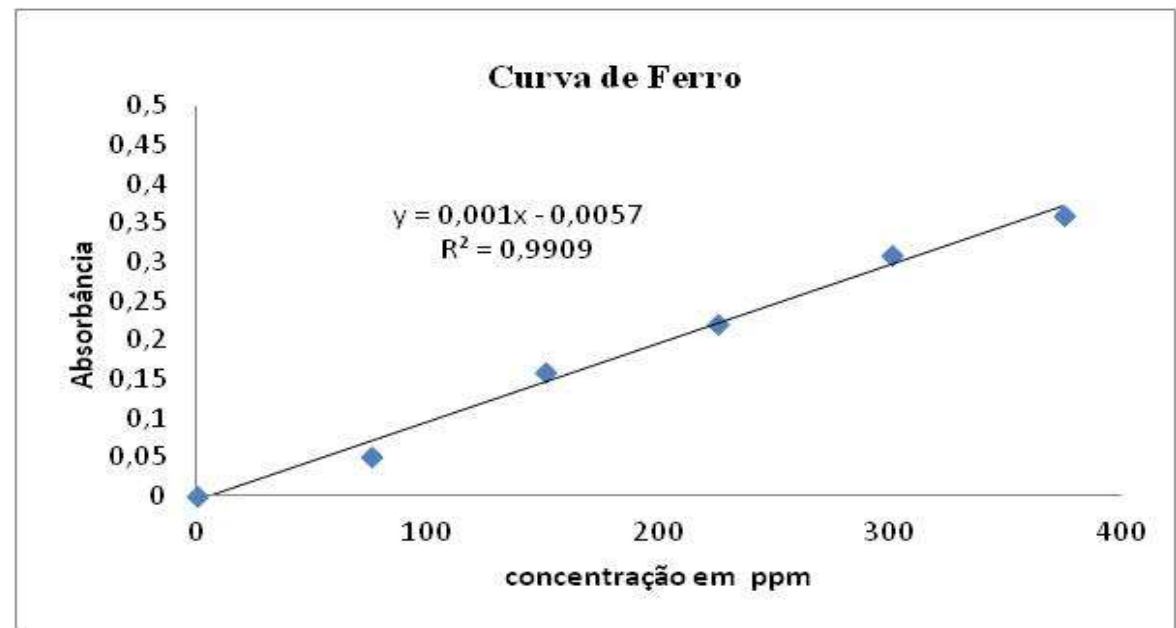

Figura 4. Curva padrão de permanganato-permanganato de potássio. 
Para a avaliação do rendimento da adsorção dos resíduos, foi realizada a leitura de todos os líquidos remanescente após a filtração em carvão ativado a partir da seguinte equação:

$$
\% R=\frac{\operatorname{Conc}(\mathrm{i})-\operatorname{Conc}(\mathrm{f})}{(\operatorname{Conc}(\mathrm{i})} \times 100
$$

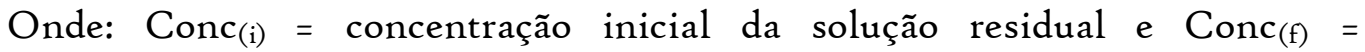
concentração final do resíduo após a filtração em carvão ativado.

\section{Caracterização do carvão obtido}

A Figura 5 A mostra o difratograma de raios-X da borra de café in natura (BCR) e do carvão ativado da borra (CABRC), Já a figura 5 B mostra os espectros de infravermelho também da borra de café residual e do carvão ativado obtido da borra de café.
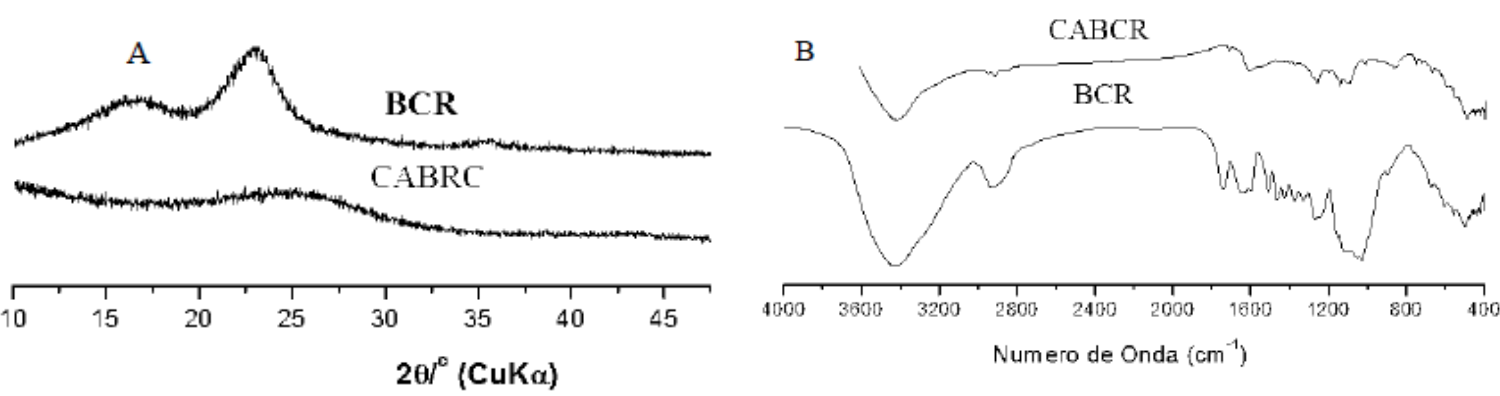

Figura 5. (A) difratograma de Raios - $X$ da orra de café e do carvão ativado, (B) espectro de FTIR da borra de café e do carvão ativado obtido da borra de café residual.

$\mathrm{Na}$ figura $5 \mathrm{~A}$ foi possível observar que as amostras apresentaram perfis alargados das reflexões típicas de material amorfo na analise de DRX. Os padrões de difração de raios-X do carvão ativado revelam que ele não é grafítico, permanecendo sempre amorfo. Essa propriedade do carvão ativado contribui para a sua característica mais única, nesse caso, a estrutura dos poros internos altamente desenvolvida e acessível. Foi possível observar resultados semelhantes ao observado 
por BRUM et al, (20II). Para a figura ${ }_{5} \mathrm{~B}$ foi possível observar as vibrações em torno de 1600 e $1400 \mathrm{~cm}^{-1}$ existente na amostra de carvão ativado (CABRC), são referentes ao estiramento de ligações $\mathrm{C}-\mathrm{C}$ e $\mathrm{C}=\mathrm{C}$ de aromáticos ou de anéis em ligninas, típicos de material carbonáceo (DE SALES et al, 2015). Comparando o FTIR da amostra de partira com o carvão ativado, foi possível observa o desaparecimento da banda e, 2900 $\mathrm{cm}^{-1}$. Sugere que a borra de café passou por uma completa carbonização.

\section{TRATAMENTO DOS RESÍDUOS POR ADSORÇÃO UTILIZANDO CARVÃO}

Os Frascos I, 2, 3 e 4 foram tratados pelo método de adsorção utilizando carvão ativado com adsorvente (Figura 6) na proporção $50 \mathrm{~g} / 100 \mathrm{~mL}$ de solução residual. Foram realizadas análises qualitativas nos resíduos líquidos antes e após o tratamento, empregando espectrometria de absorção molecular na região $U V-V$ is obtendo a concentração final de cada frasco a partir da equação da reta de cada metal e o rendimento percentual a partir da equação I.

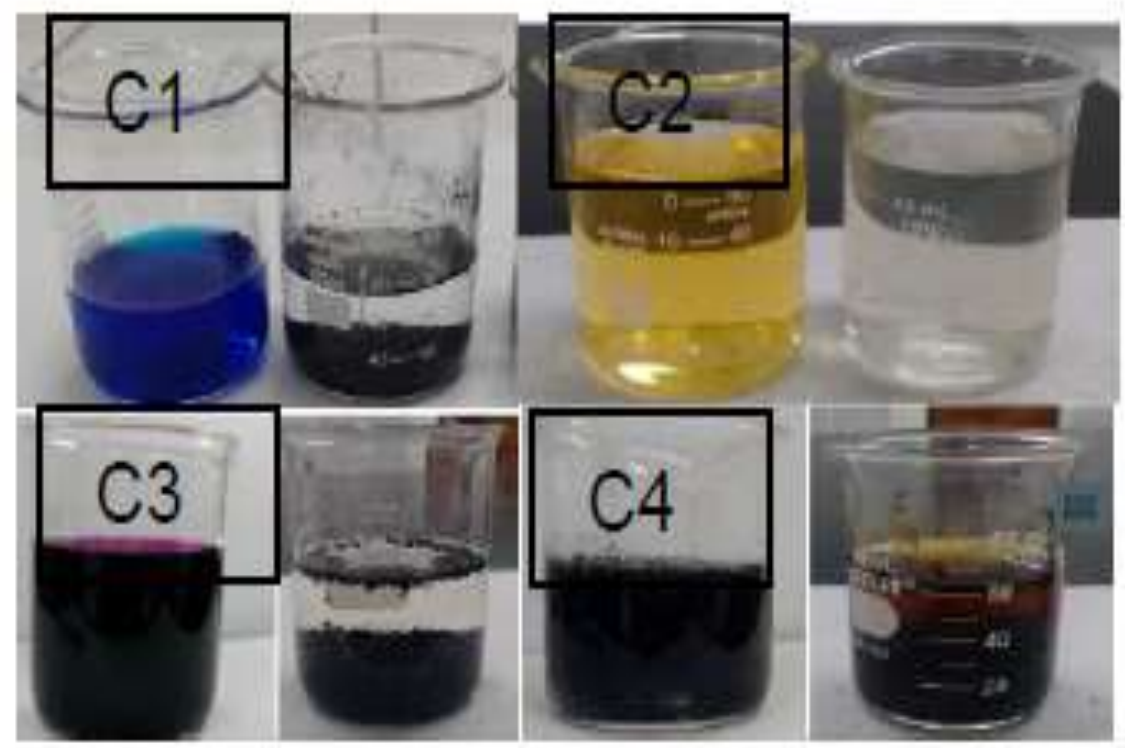

Figura 6. Ensaio de adsorção do efluente com carvão ativado: $\left(\mathrm{C}_{\mathrm{I}}\right)$ resíduo de cobre $(\mathrm{Cu})$, $\left(\mathrm{C}_{2}\right)$ resíduo de dicromato $(\mathrm{Cr}),\left(\mathrm{C}_{3}\right)$ resíduo de permanganato $(\mathrm{Mn})$ e $\left(\mathrm{C}_{4}\right)$ resíduo de ferro $(\mathrm{Fe})$. 
Foi possível observar que na Figura $6\left(\mathrm{CI}_{\mathrm{I}}\right)$, que a solução residual contendo cobre passou de azul para incolor. Possivelmente observando toda adsorção do carvão ativado frente ao metal, de acordo com esse resultado, essa amostra foi analisada por UV-visível e verificou-se que foi possível reduzir a concentração e cobre de 1590 mg/L para 0,132 mg/L. desta forma, obtendo uma redução de 99,9\% na concentração de cobre. Essa redução significativa de $0,132 \mathrm{mg} / \mathrm{L}$ de cobre encontra-se abaixo do teor máximo (I,omg/L Cu) que pode ser lançado no corpo receptor em conformidade com a resolução do CONAMA, (20II). Esse resultado é melhor que os resultados obtidos por QUEIROGA e Barbalho, (2018) é semelhante aos resultados de Bento e Paim, (2015). Porém, a recuperação de cobre nos resíduos de laboratório não gera subprodutos.

De acordo com a Figura $6\left(\mathrm{C}_{2}\right)$, observa-se que o resíduo de Cromo apresentava uma concentração bem elevada de $294 \mathrm{I} \mathrm{mg} / \mathrm{L}$ com uma coloração amarelada típica do metal em solução. Após o tratamento com o carvão ativado a coloração não é mais observada indicando que o metal foi tratado. Para confirmar essa suposição, a amostra filtrada foi analisada por UV-visível obtendo sua absorbância e calculado sua concentração do metal na curva padrão de cromo e verificou-se que a concentração de cromo passou de $294 \mathrm{Img} / \mathrm{L}$ para $0,785 \mathrm{mg} / \mathrm{L} \mathrm{com}$ rendimento de redução de cromo 99,9 \%. A concentração desse metal está abaixo dos teores máximos de lançamento de efluentes que é i,o mg/L de $\mathrm{Cr}\left(\mathrm{Cr}^{6+}\right.$ e $\left.\mathrm{Cr}^{3+}\right)$ (CONAMA, 20II).

De acordo com BENTO e PAIM, (2015). O resíduo de $\mathrm{KMnO}_{4}$ é gerado na disciplina de Química Geral Experimental I ou Analítica I, no experimento onde se determina, através de titulação redox, a concentração de $\mathrm{O}_{2}$ numa amostra comercial de $\mathrm{H}_{2} \mathrm{O}_{2}$. Na aula Química Geral Experimental I solução não é utilizada na titulação fica armazenada para posterior destinação final. No entanto, como o $\mathrm{KMnO}_{4}$ se encontra em bom estado e livre de impurezas, ele pode ser reutilizado (Bento e Paim, 2015), mas nas aulas de química Analítica $\mathrm{I}_{\text {o }} \mathrm{KMnO}_{4}$ é utilizado diretamente na tituląão redox desta forma gerando resíduos.

Na Figura 6(C3) foi possível observar que o resíduo de $\mathrm{KMnO}_{4}$ apresentava uma coloração roxa intensa de concentração inicial de 790,2 $\mathrm{mg} / \mathrm{L}$. após o tratamento com carvão ativado com agitação constante após 15 minutos foi possível observar desaparecimento da coloração típica do $\mathrm{Mn}$ na oxidação 6+. 
Para confirmar essa suposição, a amostra filtrada foi analisada por UV-visível obtendo sua absorbância e calculado sua concentração do metal na curva padrão de permanganato e verificou-se que a concentração de $\mathrm{Mn}$ passou de 790,2 $\mathrm{mg} / \mathrm{L}$ para 0,5 mg/L com rendimento de redução de cromo 99,9\%. A concentração desse metal está abaixo dos teores máximos de lançamento de efluentes que é I,o mg/L de $\mathrm{Mn}$ livre (CONAMA, 20II).

Na Figura 6( $\left.\mathrm{C}_{3}\right)$ foi possível observar que o resíduo de Ferro apresentava uma coloração de ferrugem (Amarelo escuro), devido sua oxidação com quantidades remanescente de $\mathrm{NaOH}$, de concentração inicial de $8 \mathrm{II} \mathrm{mg} / \mathrm{L}$. Após o tratamento com carvão ativado com agitação constante após 90 minutos. Foi possível observar uma pequena mudança de cor. Para cálculo da concentração final desse resíduo a amostra filtrada foi analisada por UV-visível obtendo sua absorbância e calculado sua concentração do metal na curva padrão de permanganato e verificou-se que a concentração de $\mathrm{Mn}$ passou de $8 \mathrm{II} \mathrm{mg} / \mathrm{L}$ para $490 \mathrm{mg} / \mathrm{L}$ com rendimento de redução de cromo 39,5\%. A concentração desse metal está muito acima dos teores máximos de lançamento de efluentes que é $15 \mathrm{mg} / \mathrm{L}$ de Fe (CONAMA, 20II). De acordo com Bento e Paim, (2015), para descarte de efluente acima de portaria do CONAMA, fazse necessário uma diluição ou para esse resíduo outro método de tratamento.

\section{RESULTADO DE REUSO}

A Figura 7, apresenta os resultados do teste de reuso do carvão ativado no processo de adsorção do frasco I, o mais eficiente, na proporção de 50 gramas de carvão ativado para cada roo $\mathrm{mL}$. Os resultados foram expressos a partir da turbidez da solução e demonstraram que o carvão foi capaz de realizar adsorção de 99 \% nos três primeiros ciclos, com tempo de 15 minutos com agitação constante, no quarto ciclo apesar da boa adsorção o tempo de adsorção foi de 12 horas e no quinto ciclo o tempo foi de 18 horas. Já para o sexto ciclo já não foi possível observa uma boa adsorção. A perda de adsorção observada pelo reuso do carvão ativado, pode está relatada com a obstrução dos poros do carvão, que à medida que vai sendo utilizados seus poros vão sendo bloqueados e consequentemente correndo a perda de adsorção pelo mesmo. 


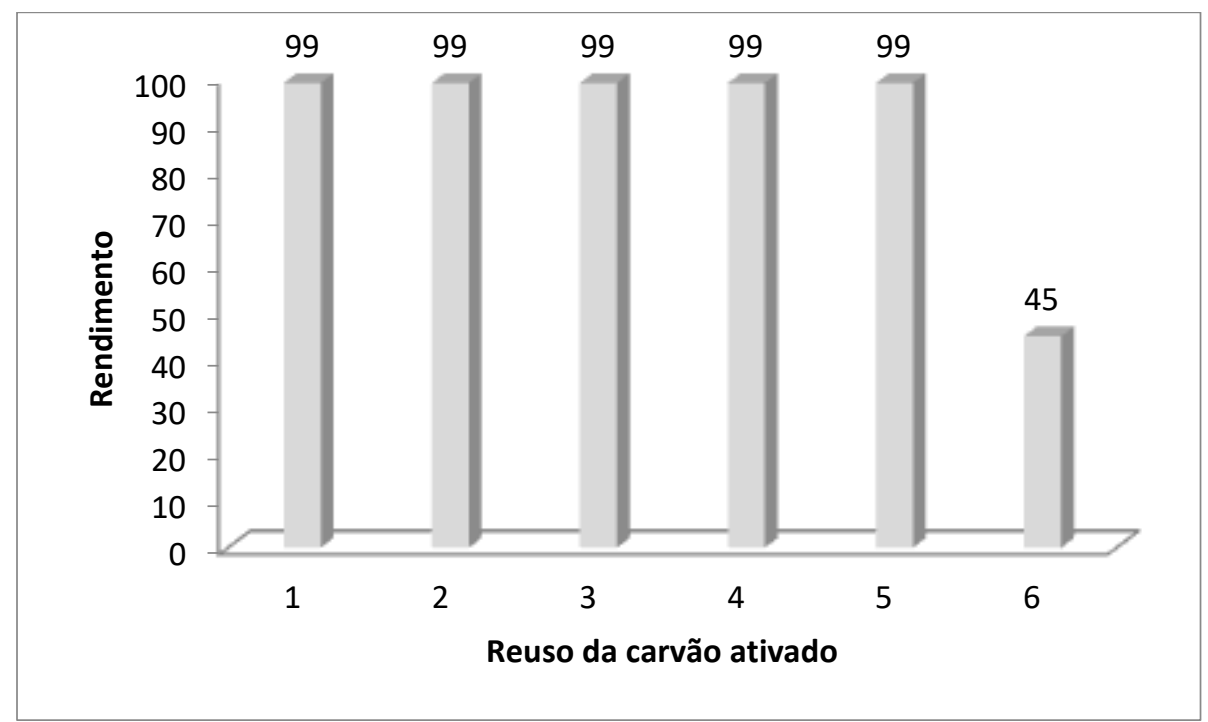

Figura 7. Teste de reuso do carvão ativado (CABCR) frente ao efluente do frasco I.

\section{CONCLUSÕES}

O estudo revelou que o carvão ativado a partir da borra de café residual apresentou uma capacidade de remoção de metais presente em efluentes de aulas de laboratórios. A partir das caracterizações de DRX e FTIR do material apresentou estrutura típica de carvão ativado. O teste de adsorção foi muito eficiente para os efluentes do Frasco r e 3 com rendimento de $99 \%$, necessitando um melhor estudo de tratamento para o efluente do frasco $\mathrm{C}_{4}$. $\mathrm{O}$ teste de reuso do carvão ativado foi possível reutilizá-lo por cinco vezes, sem a perda significativa de adsorção.

Diante dos resultados favoráveis obtidos, conclui-se que a borra de café pode ser utilizada para a produção de carvão ativado, contribuindo assim para a redução dos custos no processo de obtenção deste carvão e minimização dos impactos ambientais causados pelo despejo incorreto de efluente proveniente de aulas experimentais de ensino superior.

\section{REFERÊNCIAS}

AFONSO, J.C.; NORONHA, L.A.; FELIPE, R.P. e FREIDINGER, N. Gerenciamento de resíduos laboratoriais: recuperação de elementos e preparo para descarte final. Química Nova, v. 26, n. 4, p. 602-611, 2003. 
AFONSO, J.C.; SILVEIRA, J.A.; OLIVEIRA, A.S. e LIMA, R.M.G. Análise sistemática de reagentes e resíduos sem identificação. Química Nova, v. 28, n. I, p. 157I65, 2005 .

BENTO, W. A. S. e PAIM, A. P. S. Tratamento dos resíduos de cobre, prata, chumbo, cromo e permanganato de potássio gerados em laboratório de ensino de Química da UFPE. Ambiência, Guarapuava (PR), volume II, número I, pp. 237 - 246, 2015 .

BRUM, S. S.; DOS SANTOS, V. C.; DESTRO, P.; GUERREIRO, M. C. Esterificação de ácidos graxos utilizando zircônia sulfatada e compósitos carvão ativado/zircônia sulfatada como catalisadores. Química Nova, Vol. 34, No. 9, I5I1516, 2011 .

CONSELHO NACIONAL DO MEIO AMBIENTE - CONAMA (20II). Resolução $\mathrm{n}^{\circ}$ 430, de 13 de Maio de 20II. Dispõe sobre as condições e padrões de lançamento de efluentes, complementa e altera a Resolução no 357, de 17 de março de 2005, do Conselho Nacional do Meio Ambiente CONAMA. Diário Oficial da República Federativa do Brasil, Ministério do Meio Ambiente, Brasília, número 92, pp. 89.

DE SAlES, P. F.; BERTOLI, A. C.; PINTO, F. M.; MAGRIOTIS, Z. M. Produção, Caracterização e Aplicação do Carvão Ativado Obtido a partir do Sabugo de Milho: A Busca pelo Reaproveitamento de um Resíduo Agroindustrial. Revista Virtual Química. Vol 7, No. 4, p, I174-1188, 2015.

DI VITTA, P.B., et al. Manuseio de produtos químicos e descarte de seus resíduos. In: HIRATA, M.H., HIRATA, R.D.C., FILHO, J.M., (Ed(s)). Manual de Biossegurança. Barueri: Manole, p.67-106. 2012

FIGUERÊDO, D.V. Manual para gestão de resíduos químicos perigosos de instituições de ensino e pesquisa. Belo Horizonte: Conselho Regional de Química de Minas Gerais, 2006.

GIOVANNINI, J. G.; TAVARES, G. A.; BENDASSOlli, J. A. Avaliação das técnicas de precipitação química e encapsulamento no tratamento e destinação conjunta de resíduos líquidos contendo cromo e vidrarias de laboratório. Química Nova, Vol. 31, No. 3, 676-679, 2008.

MARINHO, C. C.; BOZOLLI, R.L.; ESTEVES. F, A. Gerenciamento de resíduos químicos em um laboratório de ensino e pesquisa: a experiência do laboratório de limnologia da UFRJ. Ecletica. Química, São Paulo, 36 , 201.

PINTO, M. V. DE S.; DA SILVA. D, L.; FONSECA, A. C. Obtenção e caracterização de carvão ativado de caroço de buriti (Mauritia flexuosa L. f.) para a avaliação do processo de adsorção de cobre (II). Acta Amazonica, vol. 42, 54I - 548, 2012. 
QUEIROGA, J. S. e BARBALHO, B. C. Recuperação de cobre a partir de resíduos gerados nas aulas práticas de química no ensino médio. HOLOS, Ano 34, vol. 02. 2018.

SANTOS, G. B.; TEDESCO, L. D.; RAVANI R. T., T. FRAGA.; R. A.; HALASZI, M. R. T. Produção de carvão ativado a partir da casca de café In: XI Congresso Brasileiro de Engenharia Química em Iniciação Científica. 2015. Unicamp. Campinas-SP.

SILVA, E. F.; ALMEIDA, A. M. de. Estudo e avaliação de descarte e tratamento de resíduos em laboratório de química numa instituição de ensino superior do centro oeste de Minas Gerais. Conexão. cient. UNIFOR-MG, Formiga, v. 8, n. I, p. 92-I02, jan./jun. 2013. 